\title{
$V O \mathbf{O} R$ E D E.
}

Das folgende Gedicht ist der erste Versuch, den der Verfasser in einer Art von Stanzen, die den Ottave rime der Italiäner ähnlich sind, gewagt hat.

Der Unterschied besteht darin, dafs, in den Stanzen, worin Bojardo, Ariost, die beiden Tasso's, Marino, und so viele andere gedichtet haben, alle Zeilen gleich viel Sylbenfüfse zählen, dafs alle Reime weiblich sind, und dafs die beiden Reime, an welche die ersten W IEIA 
sechs Zeilen gebunden sind, immer auf einerley Art abwechseln, so dafs immer die dritte und fünfte Zeile auf die erste, die vierte und sechste aber auf die zweyte reimt: da hingegen in den Stanzen des Idris 1) Jamben von acht und neun, zehn und eilf, zwölf und dreyzehn Sylben, nach Gutbefinden gebraucht werden; 2) die zwey Reime der sechs ersten Zeilen, ebenfalls nach Willkühr, bald wechselsweise verschränkt, bald auf jede andre mögliche Art zusammen geordnet sind, und endlich 3) männliche und weibliche Reime abwechseln und nach Belieben die erste oder letzte Stelle der Stanze einnehmen können.

Diese Freyheit, welche die Natur unsrer etwas ungeschmeidigen Sprache 


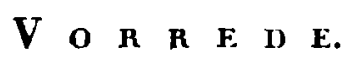

bey einem ersten Versuche wo nicht nothwendig zu machen, doch wenigstens zu entschuldigen schien, kann in den Händen eines Dichters, der mit einem Ohr für Wohlklang und Numerus begabt ist, zu einer reichen Quelle musikalischer Schönheiten werden, wodurch diese freyere Art von Stanzen einen wahren Vorzug vor den strengern Ottave rime erhält. Die Monotonie der letztern, die in einem grofsen Gedicht endlich sehr ermüden müfste, wird dadurch vermieden, und ein weit schönerer Periodenbau, mit einer sehr mannigfaltigen, oft nachahmenden, immer dem Ohre gefälligen Eurythmie und Singbarkeit (wenn ich so sagen darf) in diese Versart gebracht; Vortheile, wovon ganz gewifs kein geringer Theil des Vergnügens 
abhängt, welches auch solche Leser, die der Prosodie und Versifikazion ganz unkundig sind, an Idris und Oberon gefunden haben.

Was das Gedicht selbst betrifft, so erhielt es sein Daseyn grölsten Theils in den Jahren 1766 und 67 - oft nach langen Unterbrechungen, und unter dem Druck eines öffentlichen Amtes, dessen Geschäfte geschickter waren die Musen und Grazien zu verscheuchen als anzulocken. Die Dichtkunst war damahls für den Verfasser eine Art von Nepenthe, womit er, wie sein Horaz, von Zeit zu Zeit ein süfses Vergessen der Mühseligkeiten des geschäftigen Lebens einschlürfte. Die Besuche, die ihm scine Muse nur rerstohlncr Weise 


$$
\text { V O }
$$

geben durfte, waren selten und kurz; es war ihm also auch dabey mehr um sein eigenes Vergnügen als um fremden Beyfall und Ruhm zu thun, und diefs hatte ohne Zweifel in die Wahl des Stoffs und die Art der Behandlung desselben (worüber er sich in den ersten Stanzen hinlänglich erklärt hat) einen Einflufs, der dieses Gedicht vielleicht zu mehr Nachsicht berechtiget als es unter andern Umständen fordern könnte.

Wirklich führte derGeist Capriccio,

- ille sciens animos et pectora versans Spiritus, a capreis montanis nomen adeptus,

den Verfasser unvermerkt weiter als er Anfangs zu gehen gedachte. Was erst cin 
blofser Einfall war, wurde durch das Vergnügen, das mit einer nicht ganz unglücklichen Bekämpfung unzähliger Schwierigkeiten verbunden ist, unvermerkt zu einer angenehmen Beschäftigung. Indessen war doch schon bey der ersten Ausgabe dieser fünf Gesänge seine Meinung, dafs sie eine Art von Gegenstück zu den Vier Fakardins der Grafen Anton Hamilton bleiben sollten: und es war blofser Scherz, als er versprach, den Idris zu vollenden, so bald drey Kunstrichter und drey Prüden sich zu einer Bittschrift um Vollendung desselben unterzeichnen würden. Er bildete sich damahls wenig ein, dafs man ihn jernahls beym Worte nehmen würde, und kann sich jetzt (was auch seine Freunde sagen mögen) 


$$
\text { V O }
$$

noch weit weniger vorstellen, dafs jemand, nach Verflufs von beynahe dreyfsig Jahren, noch grausam genug seyn könnte, ein solches Versprechen gegen ihn geltend zu machen.

Alles, wozu er sich verbunden hielt, war, von den vielen und mannigfaltigen Flecken, womit die erste Ausgabe behaftet war, die folgenden nach und nach, so viel ihm möglich war, zu reinigen. Indessen hat es ihm mit aller auf die letzte Auspolierung verwendeten Zeit und Mühe dennoch nicht gelingen wollen, sich selbst ein Genüge zu thun; und Leser, die in ihren Forderungen an einen Dichter strenger sind als die meisten es zu seyn pflegen, werden hier und da noch genug kleine Unregelmäfsigkeiten 
finden, die sich nicht wegpolieren lassen wollten, und die an einem ersten Versuch in einer so schwierigen Versart vielleicht zu übersehen sind, aber keinem andern zur Entschuldigung gereichen können. 


\section{IDRIS UND ZENIDE}

\section{EIN ROMANTISCHES GEDICHT}

$$
\text { I N F Ü N F GES ÄN GEN } 1767 \text {. }
$$


